\title{
Vorwort zur Broschurausgabe
}

Als im Frühjahr 2007 die Salzburger Neidhart-Edition im Verlag De Gruyter erschien, war dies für die drei Herausgeber - Ulrich Müller, Franz Viktor Spechtler und mich - der glückliche Abschluss einer mehr als 25-jährigen Editionsarbeit, deren grundlegende Konzeption Ulrich Müller schon im Jahr 1977 erstmals präsentiert hatte. Unser gemeinsames Ziel war es, der mediävistischen Forschung mit dieser Edition erstmals die gesamte Überlieferung aller unter Neidharts Namen tradierten Texte und Melodien ohne Vorentscheidungen über ,echt' und ,unecht' zur Verfügung zu stellen, und zwar so überlieferungsnah, wie es unter den damaligen Voraussetzungen - gleichsam im Vorfeld des Übergangs zum digitalen Editionszeitalter und mit dem handlungsleitenden Ziel einer klassischen (Papier-)Ausgabe mit ihren auch verlagstechnisch-pragmatisch notwendigen Zugeständnissen - möglich war. Auf welch massive, mittlerweile längst anachronistisch erscheinende Bedenken diese der handschriftlichen Überlieferung verpflichtete Konzeption noch in den beiden letzten Jahrzehnten des ausgehenden 20. Jahrhunderts bei Teilen der mediävistischen scientific community gestoßen ist, lässt sich heute kaum noch nachvollziehen.

So glücklich wir über die sehr repräsentative Erstausgabe unserer Edition im Verlag De Gruyter waren, so deutlich war es uns auch bewusst, dass diese 3-bändige Ausgabe angesichts des durchaus stattlichen Preises nicht für jedermann und -frau erschwinglich sein würde; eine Tatsache, die in vielen Rezensionen problematisiert wurde. Das Projekt einer ,Studienausgabe“ stand dabei auch von unserer Seite aus stets im Raum; das neidhartspezifische Problem war und ist freilich, dass sie wohl unvermeidlicherweise genau jene Reduktionen des überlieferten Euvres erneuern würde, die wir mit unserer Neu-Ausgabe überwinden wollten.

Nicht zuletzt deshalb lässt sich mit dem aktuellen Projekt des Verlages De Gruyter ein langgehegter Wunsch aller Herausgeber/innen verwirklichen, nämlich unsere ursprüngliche Editionsfassung in einer erschwinglichen Version zu präsentieren. Ergänzend dazu sollen die zahlreichen vorhandenen Begleitmaterialien aktualisiert und Schritt für Schritt digital verfügbar gemacht werden. Aus dem gleichen Grund ist geplant, eine Liste der „Errata“ digital zugänglich zu machen und somit auch stets aktualisierbar zu halten. In einer für Herbst 2022 geplanten Tagung in Bamberg soll zudem der Versuch unternommen werden, eine Bilanz der Forschung 15 Jahre nach Vorliegen der Salzburger NeidhartEdition zu ziehen.

Mein herzlicher Dank gilt dem Verlag De Gruyter, insbesondere Herrn Robert Forke, für die Initiative und Realisierung dieses Projekts.

Widmen möchte ich die vorliegende Ausgabe dem Andenken an Ulrich Müller $(† 2012)$, dem sie stets ein Herzensanliegen gewesen ist. 
